\title{
Efektifitas Penerapan Aplikasi Lapor Sleman Dalam Mewujudkan Sleman Smart Regency
}

\author{
Fittia Restiane', Eko Priyo Purnomo², Lubna Salsabila ${ }^{3}$ \\ ${ }^{1}$ Departemen of Government Affairs and Administration, Jusuf Kalla School of Government, \\ Universitas Muhammadiyah Yogyakarta, Indonesia. \\ 2,3Departemen of Government Affairs and Administration, Jusuf Kalla School of Government, \\ Universitas Muhammadiyah Yogyakarta, Indonesia \\ 17Fittiara16@gmail.com, ²eko@umy.ac.id, 3lubnasalsabila@umy.ac.id
}

\begin{abstract}
Smart City as an innovation in overcoming every problem that occurs in the city. In the Smart City concept there are aspects that are Smart Regency. Is a process of management and development of a variety of natural and human resources, Smart Regency provides innovations in information technology-based grievance services, with access to the Sleman Report application, which is online complaints, aspirations, suggestions and criticisms from the public for the government. However, the services provided by the government to the community were not yet fully maximized in its implementation. The purpose of this study is to see the extent of effectiveness in the application of the Sleman Report in realizing Sleman Smart Regency in Sleman Regency. The result is quite effective for the realization of Smart Regency but in its implementation it is felt to be less than optimal because its handling is sometimes problematic. This study concludes the success of the Sleman Report Program for the steps to realize Smart Regency, the success of target users of the Sleman Report and the achievement of the Report Report in realizing the Smart Regency.
\end{abstract}

\section{Keywords: Smart City,Smart Regency, Lapor Sleman.}

Abstrak: Smart City sebagai sebuah inovasi dalam mengatasi setiap permasalahan yang terjadi di dalam kota. Dalam konsep Smart City terdapat aspek yang ada yakni Smart Regency. Adalah sebuah proses pengelolaan dan pengembangan dari berbagai macam sumber daya alam dan manusia, Smart Regency memberikan inovasi mengenai layanan pengaduan berbasis teknologi informasi, dengan akses aplikasi Lapor Sleman yakni pengaduan, aspirasi, saran dan kritik secara Online dari masyarakat untuk pemerintah. Namun dalam pelayanan yang diberikan pemerintah untuk masyarakat pun belum sepenuhnya maksimal dalam pelaksanaannya. Tujuan dari penelitian ini adalah untuk melihat sejauh mana efektivitas pada penerapan Lapor Sleman dalam mewujudkan Sleman Smart Regencyn di Kabupaten Sleman. Hasilnya cukup efektif untuk terwujudnya Smart Regency namun dalam implementasinya dirasa kurang maksimal karena penanganannya yang terkadang bermasalah. Penelitian ini menyimpulkan keberhasilan program Lapor Sleman untuk langkah terwujudnya Smart regency, keberhasilan target pengguna dari Lapor Sleman dan pencapaian tujuan Lapor Sleman dalam mewujudkan Smart Regency.

\section{Kata kunci: Smart City,Smart Regency, Lapor Sleman.}

\section{A. PENDAHULUAN}

Smart City adalah sebuah konsep kota pintar yang perencanaannya memanfaatkan perkembangan teknologi, mulai dari teknologi informasi dan teknologi informasi dan komunikasi yang akan memudahkan hidup manusia menjadi efisien dan efektif (Insani, 2017). Didalam Smart City kota mampu dengan baik mengelola sumberdaya baik sumberdaya alam maupun sumberdaya manusianya secara inovatif dan berdaya saing, dengan adanya dukungan teknologi dalam rangka mewujudkan kota pintar yang nyaman, aman dan berkelanjutan (Putri, 2018) Smart City dapat diartikan sebagai "Kota Cerdas / Kota Pintar". Di indonesia konsep Smart City sudah mulai diterapkan di beberapa Kota Besar mulai dari Surabaya, Semarang, Bandung, Bekasi, dan juga Tanggerang selatan, sedangkan Kota sedang di Indonesia yakni, Yogyakarta, Denpasar Binjai, Manado, dan Kediri, lalu ada juga Kota kecil di Indonesia yaitu Magelang, Bontang, Tual, Sawahlunto dan Bukittinggi (Winardi \& Kom, 2017). 
Dalam konsep Smart City terdapat aspek yang ada yakni Smart Regency. Adalah sebuah proses pengelolaan dan pengembangan dari berbagai macam sumber daya alam dan manusia dll. Yang terdapat di dalam kabupaten sleman yang cerdas. Sleman Smart Regency lahir dengan tujuan yang sama dengan Smart City yaitu memberikan pelayanan yang efisien dan efektif melalui pemanfaatan TIK sehingga mampu meningkaykan pada pelayanan public secara maksimal, juga dengan mendukung pembangunan yang berkelanjutan. Jika di bandingkan dengan Negara lain yaitu Republik of Korea "Dengan pengembangan sektor TIK, ROK meningkatkan informasi dan teknologi terkait infrastruktur, memperluas jaringan penjualan melalui Internet, sistem jaringan berkecepatan tinggi dan berkapasitas tinggi, menyiapkan peraturan untuk mendorong partisipasi sektor swasta, persaingan di pasar, masalah terkait tenaga kerja dan juga teknik privatisasi yang optimal. Faktor-faktor keberhasilan pembentukan dan implementasi e-government dari ROK terkait dengan infrastrukturnya dalam cara mereka mengidentifikasi infrastruktur untuk mendukung perekonomian sesuai dengan Rencana Pembangunan Lima Tahun. Selain itu peran pemimpin dan pembuat kebijakan dalam implementasi strategi yang telah ditetapkan dan juga dalam alokasi sumber daya yang menciptakan koordinasi antar kementerian dan juga kerjasama dalam mengembangkan kebijakan terkait infrastruktur. " (Salsabila \& Purnomo, 2017)

Visi dari bupati Sleman itu sendiri yaitu Drs. H. Sri Purnomo, M.SI dan wakilnya Dra. Hj. Sri Muslimatun, M.Kes. adalah "Dengan terwujudnya masyarakat sleman yang lebih mandiri, sejahtera berbudaya, sera ter-integrasikannya System E-government dalam menuju Sleman Smart Regency pada tahun 2021" (Slemankab.go.id, 2019). Penerapan Sleman Smart Regency di Kabupaten Sleman merupakan end point dalam mewujudkan kabupaten sleman sebagai kabupaten cerdas tahun 2021. Misi yang di bawa oleh bupati beserta wakilnya yakni "menerapkan prinsip solusi dari Smart City model yaitu dengan cara meningkatkan system good government dengan melakukan kemajuan secara kualitas di birokrasi yang cepat dan tanggap dalam merespon dan memberikan layanan untuk masyarakatnya, dengan melaukan peningkatan dalam menguatkan system aksesibilitas, ekonomi kerakyatan, dan juga kemampuan ekonomi rakyat dan penanggulanga kemiskinan (understanding), meningkatkan aplikasi dan integrase pada system e-government melalui tahapan yang berkelanjutan" (Slemankab.go.id, 2019).

Dalam mengimplementasikan teknologi informasi dengan baik akan mendukung sebuah capian dalam proses penentuan arah dan juga kebijakan bagi Kabupaten Sleman. Salah satunya yang sudah mengembangkan sarana pengaduan dalam bentuk elektronik yaitu Lapor Sleman. Lapor ini dibentuk untuk mewujudkan Sleman Smart Regecy yang tercantum dalam visi Pemerintah Kabupaten Sleman. Lapor Sleman di launching pada 15 Mei 2016 dan dilakukan uji coba selama sembilan bulan oleh Dinas Komunikasi dan Informatika Kabupaten Sleman. Selama kurang lebih 3,7 tahun ini E-Lapor telah memberikan banyak kegunaan bagi masyarakat terutama bagi mereka yang memperhatikan kondisi dan kelangsungan Kabupaten Sleman (Slemankab.go.id, n.d.).

Aspirasi masyarakat dapat tersampaikan kepada pemerintah, Lapor ini tidak hanya versi android tetapi dalam bentuk website, nomor telefon, media sosial dan sebagainya. Namun dalam pelaksanaannya juga mengalami permasalahan karena partisipasi masyarakat masih minim. (Slemankab.go.id, 2019). Hal ini ditunjukkan dengan data pengguna aplikasi hanya sekitar 2.500 orang dari jumlah penduduk Sleman 1.180 .479 orang, menurut bapak Helmi Arifianto selaku staf pengurus Lapor Sleman Kurangnya sosialisasi aplikasi di masyarakat juga mempengaruhi penggunaan aplikasi Lapor ini. Target pengguna Lapor Sleman menurut Helmi Arifianto selaku staf pengurus Lapor Sleman mencapai 50 persen dari jumlah penduduk Sleman. (Slemankab.go.id, n.d.)

Dari uraian diatas menunjukkan bahwa media komunikasi berbasis Aplikasi teknologi komunikasi dalam menuju Sleman Smart Regency dibutuhkan, sebagai layanan pengaduan masyarakat dengan penggunaan teknologi di dalam penggunaannya. Partisipasi masyarakat juga diharapkan mampu menunjang pencapaian tujuan dalam membangun Kabupaten Cerdas. Berdasar pada hal-hal itulah, peneliti tertarik dengan suatu kajian untuk mengetahui sejauh mana efektivitas penerapan aplikasi lapor sleman dalam mendukung Sleman Smart Regency. 


\section{B. TINJAUAN PUSTAKA}

Nadhyra M. menjelaskan bahwa Bandung Smart City telah menerapkan 10 dimensi Smart City yang telah direncanakan dengan total keseluruhan 62 program (Putri, 2018). Selanjutnya Tanjung K.P Aplikasi Lapor Sleman kepada masyarakat terfokus pada memberikan informasi (Pangesti, 2018). Pendapat Anang S. terkait preparation and development of regency regency sleman smart 2021 penggunaan yang paling penting adalah indikator tata kelola yang cerdas (Setiawan, 2018). Menurut Anggit A. Smart UMKM Mendukung Sleman Smart Regency dan dampaknya berpengaruh bagi pembangunan Kabupaten cerdas (Amrullah \& Utami, 2018).

Dalam Sugeng W membahas "Perencanaan pengembangan, sehingga berhasil atau tidaknya perencanaan ini tergantung factor komitmen dari dalam Pemerintah Kabupaten Sleman Itu sendiri” (Winardi \& Kom, 2017). Lalu jurnal Arin N. Suci S. membahas mengenai sistem informasi pada "LAPOR!" Di UKP4 adalah efektif. Sedangkan untuk skala sangat efektif dimiliki oleh dimensi penggunaan dan pada indikator cukup efektif adalah kualitas pelayanan (Sitoresmi, 2013). Rahcmawati H. juga mengatakan "dampak penerapan aplikasi Lapor Sleman sebagai pelayanan pengaduan menjadi lebih transparan, efektif dan efisien" (Rachmawati et al., 2018).

\section{Kerangka Teori}

\section{Efektivitas}

\section{a) Definisi Efektivitas}

J.P Campbell (1998) mendefinisikan efektivitas sebuah tingkat kemampuan dari suatu organisasi untuk bisa melaksanakan semua tugas pokoknya atau untuk dapat mencapai sebuah sasaran yang telah ditentukan sebelumnya. Sedangkan definisi lainya menurut Hidayat (2006) efektivitas merupakan alat untuk mengukur capaian (kualitas, kuantitas, serta waktu) yang telah tercapai. Jika semakin besar persentase sasaran yang didapatkan, maka akan semakin tinggi efektivitasnya. Dari beberapa pendapat tersebut peneliti menyimpulkan bahwa efektivitas adalah salah satu indikator tercapainya tujuan yang ditentukan dari pelaksanaan sebuah program ataupun kebijakan yang telah dilaksanakan.

\section{b) Konsep Efektivitas}

Penelitian ini mengacu pada beberapa aspek yang dijelaskan oleh Campbell (1989:121) dimana bertujuan untuk mendapatkan gambaran yang jelas mengenai Efektivitas Lapor Sleman dalam Mewujudkan Sleman Smart Regency, yaitu sebagai berikut :

1) Keberhasilan Program

Merupakan kesatuan dalam upaya tercapinya kegiatan dengan mudah dan sesuai dengan apa yang di harapkan dan memiliki dampak yang positif terhadap program Lapor Sleman yang direncanakan di Kabupaten Sleman.

2) Keberhasilan target

Membentuk suatu unit dalam pengaduan dimana masyarakat mengetahui dan memahami bentuk dari pelayanan yang sesuai dengan apa yang diterima masyarakat pengguna layanan Lapor Sleman dapat merespon tanggapan terkait layanan dengan memberikan saran, kritikan maupun aduan prihal pelayanan.

3) Pencapaian tujuan

Tujuan merupakan keseluruhan dari hasil akhir yang akan dicapai. Sebagai tolak ukur yang digunakan dalam mengukur keefektivitasan program sehingga seluruh proses yang dilakukan sesuai dengan tujuan.

\section{Smart Regency}

Smart regency atau kabupaten pintar merupakan turunan secara langsung apa yang menjadi maksud Smart City yang dicanangkan untuk diimplementasikan konsepnya, oleh kota-kota yang ada di dunia. Termasuk di dalamnya di salah satu daerah Kabupaten di Indonesia yang bernama Kabupaten Sleman. Bahwa keinginan besar Kabupaten Sleman yaitu "terciptanya masyarakat di Kabupaten Sleman yang 
lebih mandiri, berbudaya, sejahtera, dan terintegrasikannya sistem e-government untuk menuju pada Smart Regency di tahun 2021" (Setiawan, 2018). Menurut Perbup Sleman Nomer. 1.1 Tahun 2018 terkait "Pengembangan Masterplan Smart City Kabupaten Sleman Tahun 2017-2021" dalam pasal 1 point 2. Menyebutkan "Sleman Smart Regency ialah Kabupaten Sleman yang pintar dalam meningkatkan kualitas sumber daya (alam, manusia, waktu, dan lainnya) untuk digunakan cepat dan tepat dengan memanfaatkan TIK sehingga dapat memaksimalkan pelayanan publik serta mendukung pembangunan yang berkelanjutan".

Menurut Winardi (2017: 107), bahwa penerapan teknologi pada Smart Regency memiliki elemen atau indikator yang menyusunnya pada pengelolaan pemerintahan yaitu:

1) Smart Government Guna mendukung terciptanya Smart City, kantor istansi pemerintahan harusnya menjadi kantor yang smart, dengan adanya kemudahan-kemuhdahan dalam proses birokrasi dengan memaksimalkan atau memanfaatkan adanya layana TIK. Diantaranya ialah E-Arsip, E-room manajemen, E-money, dan E-networking.

2) Smart Public Services merupakan layanan yang dimaksudkan untuk memudahkan masyarakat dalam menikmati pelayanan publik. Diantaranya ialah Citizens Apps, E-Survei, E-Complain.

3) Smart Health adalah pelayanan guna men-drive kebiasaan atau perilaku sehat pada masyarakat. Pada pelayanan smart health ini juga terhubung pada pelayanan yang ada di fasilitas pelayanan kesehatan dan rujukan. Diantaranya ialah E-Registration, E-outbreak, dan pendaftaran nomor antrian periksa di RSUD Sleman melalui Whatsapp.

4) Smart Education merupakan pelayanan secara online yang bersifat interaktif dalam bidang pendidikan. Layanan Smart Education meliputi eLearning (Pembelajaran Online), layanan penelitian secara online, dan bantuan beasiswa pendidikan. Yaitu E-learning, E-research, dan E-Schoolarship.

5) Smart Tourism adalah layanan wisata pintar yang dilakukan oleh warga di Kabupaten Sleman untuk para wisatawan local dan asing. Dengan memberikan layanan interaktif yaitu dengan menunjukkan konten yang informative berbentuk: daftar kuliner, daftar wisata di Sleman, kerajinan khas Sleman, desa wisata, pertunjukan kesenian daerah, dan pendukung wisata lain yang informatif dan interaktif (tarif, harga, jam operasional, kontak person, rating pengunjung).

\section{METODE PENELITIAN}

Dalam penelitian ini maka peneliti akan menggunakan metode penelitian kualitatif dengan menggunakan data sekunder berupa buku, jurnal akademis, artikel, tesis, disertasi, penelitian terdahulu serta sumber-sumber lainnya yang relevant dengan penelitian yang akan dilakukan sekarang. "Penelitian studi kasus adalah pendekatan kualitatif yang penelitinyamengeksplorasi kehidupan nyata, sistem terbatas kontemporer (kasus) atauberagam sistem terbatas (berbagai kasus), melalui pengumpulan data yang detaildan mendalam yang melibatkan beragam sumber informasi atau sumber informasimajemuk (misalnya, pengamatan, wawancara, bahan audiovisual, dan dokumendan berbagai laporan), dan melaporkan deskripsi kasus dan tema kasus" (Creswell \& W, 2015).

Dengan mneggunukan penelitian kualitatif penulis bertujuan untuk "Mendefinisikan dan membatasi masalah agar lebih fokus dan memiliki ketajaman analisa. Melengkapi fenomena tersebut dengan sebuah kajian ilmiah, terkait etika penulisan ilmiah tidak dalam rangka pembuktian teori. Menggambarkan penelitian yang pernah dilakukan sebelumnya sebagai tanda adanya keberagaman fenomena yang akan diteliti. Mengarahkan pemilihan metode dan cara pengambilan data terkait dengan penentuan prosedur pengambilan analisis data" (Tobing et al., 2016). Data yang diperoleh kemudian akan dianalisis dengan cara mencatat data-data serta informasi secara obyektif serta apa adanya yang diperoleh dengan cara menganalisis pada data sekunder sesuai dengan fokus penelitian yang dilakukan dengan menggunakan tinjauan studi kasus terdahulu dapat membantu serta mendukung dalam melakukan penelitian.

Selanjutnya peneliti akan menyajikan data yang telah di rangkum sesuai dengan fokus penelitian kemudian akan disusun dengan cara diuraikan secara jelas melalui teks naratif, 
grafik, bagan, dan sebagainya. Data yang diperoleh dari studi kepustakaan ini akan digunakan menjadi dasar atau pedoman dalam proses penelitian. Secara singkat penelitian ini pertama akan berfokus pada pembahasan pemaparan dasar mengenai efektivitas aplikasi Lapor Sleman, Setelah itu peneliti akan melanjutkan menganalisis pemaparan data-data berdasarkan teori yang ada mengenai aplikasi Lapor Sleman. Setelah itu diakhir peneliti akan menyimpulkan dari data-data yang telah dianalisis apakah aplikasi Lapor Sleman dapat dikatakan efektif atau tidak.

\section{HASIL DAN PEMBAHASAN}

\section{Sleman Smart Regency}

Sleman Smart regency adalah konsep yang dilakukan oleh kabupaten Sleman untuk membentuk Sleman yang cerdas dalam pengelolaan serta pengembangan pada sumber daya (manusia, alam, waktu dan lainnya) (Slemankab.go.id, n.d.). agar penggunaannya dapat secara efektif dan efisien dengan memanfaatkan teknologi informasi yang ada serta teknologi komunikasi, sehingga kabup (htt)aten tersebut bias lebih memaksimalkan pelayanan publik dan mendukung pembangunan yang berkelanjutan.

Dalam Pembangunan Smart city Kabupaten Sleman Terdapat 6 Elemen dalam pengembangan Sleman Smart Regency yakni:

1. Smart Governance

Merupakan tata kelola pemerintahan yang cerdas, yang mencakup didalamnya pelayanan publik, seperti : system informasi penerimaan peresta didik baru untuk tingka SMP di Sleman yang terintegrasi secara online dan real time (E-ppdb), Mobile pbb, Lapor Sleman, Sleman Tv, dan Sistem perijinan online.

2. Smart Branding

Yaitu peningkatan pada nilai jual daerah secara cerdas, seperti : produk atau layanan dari Kabupaten Sleman dalam mempromosikan pengelolaan potensi yang ada produknya seperti, Sleman Creative Space, branding "sleman the Living Culture", Branding "Beras Sleman', dan Kopi Merapi.

3. Smart Economy

Sinergi pembangunan ekonomi secara cerdas adalah mengenai produk dan layanan yang ada di Kabupaten Sleman, seperti : rumah kreatif sleman, revitalisasi pasar tradisional, dan harga pangan (e-pangan).

4. Smart Living

Dukungan pada pengelolaan ekosistem tempat kehidupan yang cerdas, seperti : SES (sleman emergency service), E-pasien, dan Lasamba.

5. Smart Society

Terwujud dari partisipasi cerdas masyarakat, seperti : e-library, system katalog informasi pada buku di perpustakaan (OPAC), Ngantar Paimah (pelayanan antar sampai rumah), balai latihan kerja, dan e-ppid.

6. Smart Environment

Tata kelola pada sumber daya alam serta pemeliharaan lingkungan yang cerdas, seperti : Pengelolaan ruang terbuka hijau (RTH), dan Smart PJU.

Menurut (Setiawan, 2018) Setelah dirumuskannya perencanan smart regency maka perlu adanya aksi terkait terciptanya perencanaan sleman smart regency. Dalam tahun 2017 - 2026 rencana aksi untuk merealisiskan perencanaan sleman smart regency sebagai berikut:

1. Pengembangan Kebijakan dan Kelembagaan

- Penyusunan Masterplan

- Pembentukan Dewan dan Tim Smart Regency

- Pembentukan Forum Smart Regency

- Kemitraan antara pemerintah, perguruan tinggi, bisnis, media, dan komunitas.

2. Pembangunan Infrastruktur

- Fasilitas publik

- Infrasruktur TIK

- Peningkatan kapasitas bandwidth

3. Penguatan Literasi

- Peningkatan kapasitas SDM aparat

- Literasi masyarakat 
IJSE - Indonesian Journal on Software Engineering, Vol.6, No.1, Juni 2020, 1-11

pISSN: 2461-0690 I elSSN: 2714-9935

- Sinergi dengan komunitas

4. Pengembangan Aplikasi dan Perangkat Lunak

- Keamanan informasi

- Aplikasi layanan publik

- Aplikasi kewilayahan

- Aplikasi layanan kepemerintahan

Dalam rencana aksi Smart Regency di Sleman tahun 2017-2026 tentang pengembangan aplikasi dan perangkat lunak yaitu aplikasi layanan publik, maka Kabupaten Sleman menciptakan aplikasi Lapor Sleman. Aplikasi Lapor Sleman adalah kanal aduan sebagai layanan publik yang digunakan untuk berkomunikasi dua arah dengan pemerintah. Salah satu syarat peningkatan kualitas pelayanan publik, dimulai dengan menempatkan masyarakat sebagai poin sentral dalam setiap langkah pembangunan. Sleman mengadaptasi keterlibatan masyarakat dalam upaya pengawasan dan evaluasi kegiatan pembangunan melalui aplikasi Lapor Sleman yang ditujukan untuk memberikan kesempatan bagi masyarakat berpartisipasi dalam mewujudkan Sleman yang lebih baik.

\section{Aplikasi Lapor Sleman}

Lapor Sleman merupakan aplikasi wujud inovasi bagian dari Sleman Smart Regency. Aplikasi ini memiliki tujuan untuk memberikan kemudahan bagi masyarakat kabupaten sleman dan pemerintah kabupaten Sleman untuk bisa berkolaborasi dalam menyelesaikan berbagai permasalahan yang ada di Kabupaten Sleman. Dengan aplikasi Lapor Sleman ini, warga diberikan kemudahan untuk memberikan laporan dalam bentuk sebuah aspirasi, kritik, saran dan keluhan kepada pemerintah. Selanjutnya kemudahan juga di dapat oleh masyarakat yaitu dalam meminta serta mendapatkan informasi dan penjelasan oleh pemerintah Kabupaten Sleman dengan respon yang cepat dan nyaman. Tidak hanya mempermudah masyarakat saja namun pemerintah juga mendapatkan kemudahan dalam dalam memahami permasalahan yang dialami oleh masyarakat sehingga pemerintah dapat dengan cepat melakukan perencanaan dan perbaikan permasalahan masyarakat di lapangan.

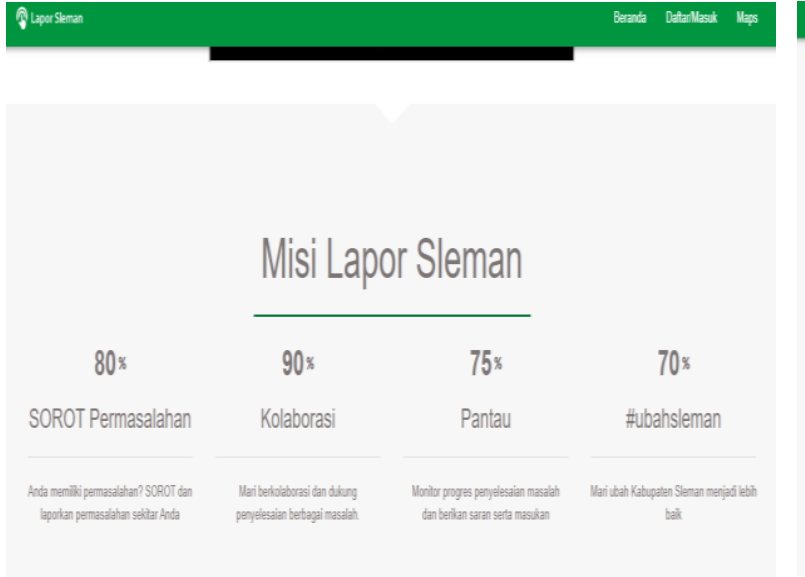

a.

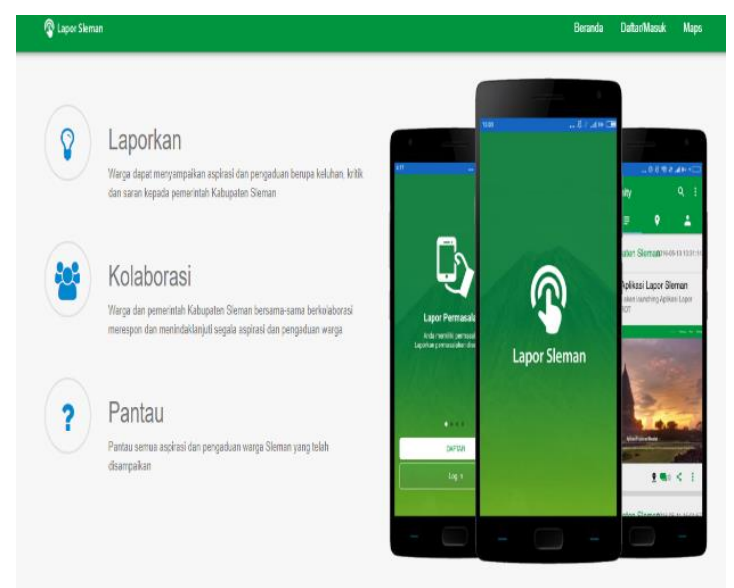

b.

Gambar 1. Aplikasi Lapor Sleman

(a). Misi Aplikasi Lapor Sleman; (b). Tampilan Aplikasi Lapor Sleman

Sumber : https://lapor.slemankab.go.id/

Dalam system Lapor Sleman setidaknya ada 53 OPD yang terintegrasi dengan Lapor Sleman sehingga aduan atau laporan yang masuk bias langsung dilihat dan di tanggapi oleh OPD terkait antara lain: 
Tabel 1. Daftar Nama 53 OPD Terintegrasi pada Lapor Sleman

\begin{tabular}{|c|c|c|c|}
\hline NO & NAMA OPD & NO & NAMA OPD \\
\hline$\overline{1}$ & $\overline{\text { DPUPKP }}$ & $\overline{28}$ & $\overline{\mathrm{BKPP}}$ \\
\hline$\underline{\underline{2}}$ & DISHUB & $\underline{29}$ & DISPORA \\
\hline$\underline{\overline{3}}$ & DISDUKCAPIL & 30 & Kec. Berbah \\
\hline$\overline{4}$ & $\overline{\text { Dinas Lingkungan Hidup }}$ & $\overline{31}$ & $\overline{\overline{D I S B U D}}$ \\
\hline$\underline{5}$ & Dinas PMPPT & $\underline{32}$ & Dinas Pariwisata \\
\hline$\underline{6}$ & HUMAS Kab. Sleman & $\underline{33}$ & INSPERKTORAT \\
\hline$\underline{7}$ & $\overline{\text { DSIKOMINFO }}$ & 34 & Kec. Godean \\
\hline$\overline{8}$ & DINSOS & $\overline{35}$ & Kec. Ngaglik \\
\hline$\underline{9}$ & DINKES & $\underline{36}$ & Kec. Ngemplak \\
\hline$\underline{10}$ & SATPOL PP & $\underline{37}$ & BAPPEDA \\
\hline$\overline{11}$ & DInas Perindag & $\overline{38}$ & Kec. Kalasan \\
\hline$\overline{12}$ & PDAM & $\underline{\overline{39}}$ & Kec. Seyegan \\
\hline$\underline{13}$ & BKAD & $\underline{40}$ & RSUD Sleman \\
\hline 14 & $\overline{\text { Dinas PMD }}$ & 41 & Kec. Minggir \\
\hline 15 & DISDIK & 42 & Kec. Pakem \\
\hline 16 & Dinas PERPARI & $\overline{43}$ & Kec. Sleman \\
\hline$\overline{17}$ & $\overline{\text { Badan PLH }}$ & $\overline{44}$ & Setwan DPRD \\
\hline$\underline{\overline{18}}$ & Kec. Depok & $\underline{\overline{45}}$ & DInas KEbersihan \\
\hline 19 & Badan KESBANGPOL & $\underline{46}$ & DInas P3AP2KB \\
\hline$\overline{20}$ & Kec. Gamping & $\overline{47}$ & Kec. Cangkringan \\
\hline$\underline{21}$ & DPTR & 48 & Kec. Moyudan \\
\hline$\underline{22}$ & Dinas KUKM & 49 & Kec. Prambanan \\
\hline$\overline{23}$ & $\overline{\text { DISNAKER }}$ & 50 & Kec. Tempel \\
\hline 24 & KEc. Mlati & $\underline{51}$ & Kec. Turi \\
\hline 25 & BPBD & $\underline{52}$ & SETDA \\
\hline$\overline{26}$ & Perpustakaan daerah & $\overline{53}$ & Dinas Perpus dan Arsip \\
\hline$\underline{27}$ & RSUD Prambanan & & \\
\hline
\end{tabular}

Sumber : https://dash.slemankab.go.id/lapor/

\section{Efektivitas penerapan Lapor Sleman}

Penelitian ini mengacu pada beberapa aspek yang dijelaskan oleh Campbell (1989:121) dimana bertujuan untuk mendapatkan gambaran yang jelas mengenai Efektivitas Lapor Sleman dalam Mewujudkan Sleman Smart Regency. Hasilnya sebagai berikut :

1. Keberhasilan Program

Kemudahan layanan aplikasi lapor sleman dan banyaknya fasilitas pendukung menjadikan hal ini sebagai salah satu indikator keberhasilan layanan aduan yang disediakan Pemerintah Kabupaten Sleman. Pada pelaksanaannya aplikasi ini dapat diakses melalui smartphone yang dimiliki masyarakat. Pada prosedur yang dimiliki juga mudah dimengerti oleh masyarakat karena pengguna layanan aduan di Kabupaten Sleman. Kebebasan yang diberikan kepada masyarakat untuk bertanya, menyampaikan keluhan, masukan, aspirasi dan saran membantu pemerintah daerah Kabupaten Sleman dalam memperbaiki pelayanan publik terhadap masyarakat didaerahnya.

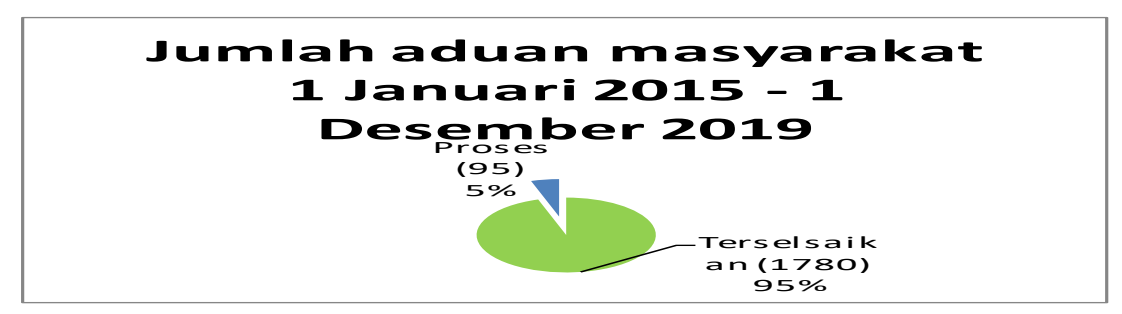

Gambar 2. Statistik data jumlah aduan masyarakat Sumber : https://dash.slemankab.go.id/lapor/ 
Melihat dari data di atas di jelakan bahwasannya dari 1.875 laporan yang masuk terhitung dari 1 januari 2015 sampai dengan desember 2019 tercatat 1.780 laporan telah terselesaikan permasalahannya, sedangkan 95 laporan atau aduan dari masyarakat pengguna Lapor Sleman masih dalam proses. Artinya laporan yang di lakukan oleh masyarakat selalu di respon oleh pemerintah kabupaten Sleman, sehingga ini adalah langkah baik dalam konsep Sleman Smart Regency.

2. Keberhasilan Target

Kefektifan layanan lapor dapat dilihat dari website pemkab Sleman diamana sampai saat ini tanggapan terkait Lapor Sleman mencapai 1.946 tanggapan. Dari beberapa tanggapan atau aduan yang ada, beberapa ada yang menanyakan terkait aturan dan juga melaporkan. masalah masalah yang ada di lingkungan baik lingkungan rumah atau lingkungan birokrasi.
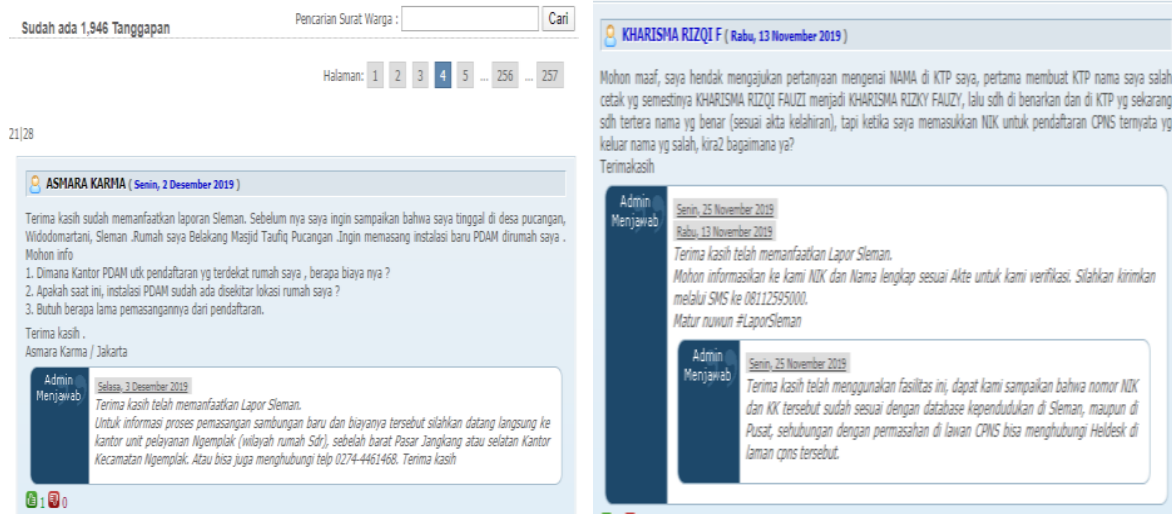

Gambar 3. Tanggapan pada Aplikasi Lapor Sleman

Sumber : http://www.slemankab.go.id/surat-warga

Akibat dari pemanfaatan pada aplikasi Lapor Sleman yaitu masyarakat merasa pemerintah lebih memeperhatikan sehingga menimbukan rasa kepercayaan dan kemauan masayarakat unruk dapat menyampaikan aduan, laporan serta aspirasinya. Timbulnya rasa kepercayaan masyarakat atas kinerja dari pelayanan yang diberikan oleh pemerintah menjadi modal yang baik dalam menjalankan program-program pmemerintah guna mencapai peningkatan pelayana terhadap masyarakat..

3. Pencapaian tujuan

Berdasarkan tujuan aplikasi Lapor sleman yang dijabarkan pada google play store yakni aplikasi Lapor Sleman memiliki tujuan untuk mempermudah warga dalam menyuarakan aspirasi serta pengaduan terkait keluahan, kritik dan saran kepada Pemerintah Kabupaten Sleman. Kemudian masyarakat dan pemerintah bersamasama melakukan kolaborasi untuk merespon dan menindaklanjuti segala bentuk aspirasi dan pengaduan masyarakat. Namun dalam tujuan tersebut berdasarkan hasil penelitian terkait aplikasi Lapor Sleman justru masih terdapat kelemahan yang menyebabkan masalah.

Namun tidak hanya itu, kelemahan-kelemahan dari aplikasi Lapor Sleman pun masih banyak di keluhkan oleh masyarakat sleman dari mulai rumitnya proses dalam pelaporan, lambatnya penanganan dari aplikasi Lapor Sleman. Menyikapi permasalahan tersebut Kepala Dinas Informasi dan Komunikasi Sleman mengakui 
masih adanya beberapa kendala yang harus di benahi terkait layanan aplikasi Lapor Sleman. Akan tetapi menurut Kepala Dinas Komunikasi dan Informasi Kabupaten Sleman saat di menjelaskan keterangan adanya permasalahan di layanan aplikasi Lapor Sleman, Dirinya mengungkapkan bahawannya "Memang banyak problem yang dialami masyarakat saat mengakses apliakasi. Namun ketika aplikasi tidak bisa, masyarkat dapat mengadukan melalui website atau media sosial seperti IG, Facebook atau Twitter Pemkab Sleman" (https://www.antaranews.com/berita/802676/layanan-online-lapor-sleman-masihbanyak-dikeluhkan-masyarakat diakses pada 7 Desember 2019, pukul 17.18 WIB).

Sering terjadi masalah atau eror pada Aplikasi Lapor Sleman, dimana para pengguna tidak dapat membaca komentar, berkomentar, mengganti profil dll. Hal ini yang harus lebih diperhatikan oleh Dinas Kominfo Kabupaten Sleman terkait Aplikasi yang mengalami troble.

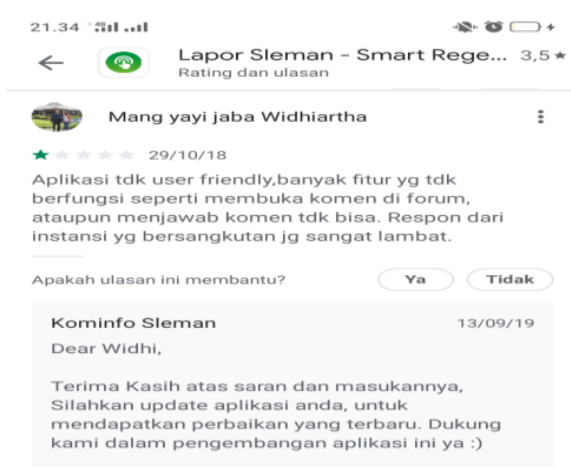

Gambar 4. Rating dan Ulasan Lapor Sleman Sumber : https://lapor.slemankab.go.id/

Lalu terkait penyederhanaan Aplikasi Lapor sleman sendiri, dalam peneliti (Hapsari, A. N., 2018) mengatakan bahwa Aplikasi Lapor Sleman belum bias digunakan pada keadaan darurat, sehingga harus ada pembaharuan Aplikasi agar dapat menggunakan fitur baru, agar lebih User Frendly dalam penggunaannya.

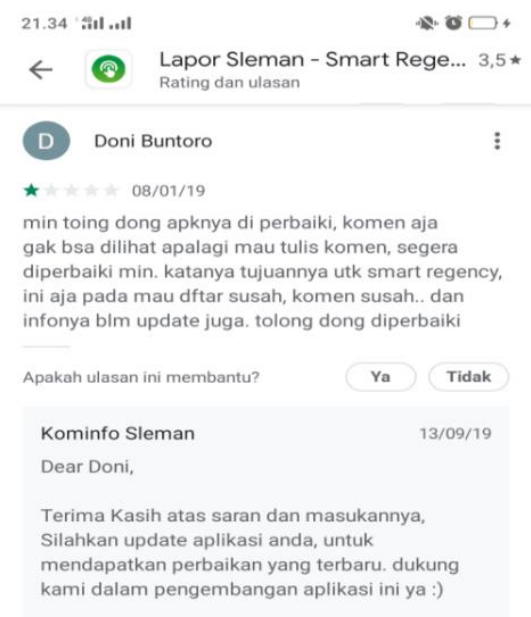

Gambar 5. Rating dan Ulasan Lapor Sleman Sumber : https://lapor.slemankab.go.id/ 


\section{E. KESIMPULAN}

Penerapan Lapor Sleman dalam mewujudkan Sleman Smart Regency di rasa sudah cukup efektif. Namun dalam implementasinya dirasa masih kurang maksimal dalam pelayanan yang di berikan oleh pemerintah Kabupaten Sleman karena masih terdapat kelemahan yang ada pada Lapor Sleman yaitu lambatnya penanganan terkait pengaduan yang dilakukan oleh masyarakat dan aplikasi yang kadang bermasalah. Selain itu sosialisasi yang kurang mungkin menjadikan masyarakat kurang paham akan adanya aplikasi Lapor Sleman, di lain sisi kualitas aplikasi yang kadang terganggu membuat masyrakat menjadi enggan menggunakan aplikasi Lapor Sleman. Tanggapan yang lambat juga membuat masyarakat kurang puas terhadap layanan Lapor Sleman, sebaiknya pemerintah Kabupaten Sleman lebih tegas dalam menugaskan ASN yang bertanggung jawab atas pemberian tanggapan atau jawaban pada Lapor Sleman.

Namun untuk menyiasati itu semua Dinas Kominfo Kabupaten Sleman menyiapkan website dan media sosial untuk masyarakat menyampaikan aspirasi, masalah dan keluh kesah terkait pelayanan yang ada di masyarakat. Sosial media yang disipkan oleh Dinas Kominfo Kabupaten Sleman adalah melalui Facebook, Twitter, email, website dan SMS hotline yang bias saja menjadi alternative bagi masyarakat untuk lebih bias menyampaikan permasalahan dan aspirasinya pada pemerintah Kabupaten Sleman demi mencapai tujuan Sleman Smart Regency.

\section{REFERENSI}

amrullah A, Utami E. 2018. Perancangan Sistem Informasi Pada Smart Umkm Dalam Mendukung Sleman Smart Regency. Konf. Nas. Sist. Inf. 2018 0: 8-9.

Campbell. (1989). Riset Dalam Efektifitas Organisasi. Jakarta: Erlangga.

Edam, N. S., Pangemanan, S., \& Kairupan, J. (2018). Efektivitas Program Cerdas Command Center Sebagai Media Informasi Masyarakat Dalam Rangka Pelayanan Publik (Studi Di Kantor Walikota Manado). Jurnal Eksekutif, 1(1).

Creswell \& W. (2015). 30 Essential Skills For The Qualitative Researcher - John W. Creswell Google Buku. Https://Books.Google.Co.Id/Books?HI=Id\&Lr=\&Id=Sulscgaaqbaj\&Oi=Fnd\&Pg=Pp1\&Dq=R elated:Fv2ev6ph0qyj:Scholar.Google.Com/\&Ots=5b_Sbdrqgb\&Sig=WIdvq1Iriqzvlzpc3uo7 oan9uyo\&Redir_Esc $=Y \# \mathrm{~V}=$ Onepage\&Q\&F=False

Dashboard Lapor Sleman. (N.D.). Retrieved December 21, 2019, From Https://Dash.Slemankab.Go.Id/Lapor/

Hapsari, A. N., \& Rachmawati, R. (2018). Pemanfaatan Aplikasi Lapor Sleman Sebagai Pelayanan Pengaduan Di Kabupaten Sleman. Jurnal Bumi Indonesia, 7(1).

Hudjolly, H. (2017). Epistemologi Dalam Kebijakan Publik: Kajian Konsep Smart City Di Indonesia. Untirta Civic Education Journal, 2(1).

Insani Pa. 2017. Mewujudkan Kota Responsif Melalui Smart City Priskadini April Insani. Vol. 2, Nomor 1, April 2017 Publisia (Jurnal Ilmu Adm. Publik) 2: 25-31.

Pangesti, T. K. (2018). Strategi Pemerintah Kabupaten Sleman Dalam Mengkomunikasikan Aplikasi Lapor Sleman Sebagai Upaya Mewujudkan Smart City Tahun 2017.

Pemerintah Kabupaten Sleman » Informasi Publik. (N.D.). Retrieved December 8, 2019, From Http://Www.Slemankab.Go.Id/Informasi-Publik

Pemerintah Kabupaten Sleman " Lapor Sleman. (N.D.). Retrieved December 9, 2019, From Http://Www.Slemankab.Go.Id/Surat-Warga

Pemerintah Kabupaten Sleman " Profil Bupati Dan Wakil Bupati Sleman 2016 - 2021. (N.D.). Retrieved December 7, 2019, From Http://Www.Slemankab.Go.Id/Profil-Bupati-Dan-WakilBupati-Sleman-2016-2021

Pemerintah Kabupaten Sleman » Sistem Informasi. (N.D.). Retrieved December 8, 2019, From Http://Www.Slemankab.Go.Id/Sistem-Informasi

Primanda, R. Efektivitas Program Sms Gateway Pada Masyarakat Oleh Dinas Kependudukan Dan Pencatatan Sipil Kabupaten Bintan.

Putri Nm. 2018. Implementasi Konsep Smart City Di Kota Bandung Dan Faktor-Faktor Yang Mempengaruhinya Nadhyra Maharani Putri. 1-14.

Rachmawati R, Ramadhan Er, Rohmah A 'Ainur. 2018. Aplikasi Smart Province "Jogja Istimewa": Penyediaan Informasi Terintegrasi Dan Pemanfaatannya. Maj. Geogr. Indones. 32: 14. 
Ramadhan, E. (2017). Peringkat Smart City Dan Komponennya Pada Kota-Kota Metropolitan Di Indonesia (Doctoral Dissertation, Universitas Gadjah Mada).

Salsabila, L., \& Purnomo, E. P. (2017). Establishing And Implementing Good Practices EGovernment (A Case Study: E-Government Implementation Between Korea And Indonesia). Asean/ Asia Academic Society International Conference (Aasic), 5, 221-229.

Setiawan A. 2018. Preparation And Development Of "Smart Regency" Regency Sleman.

Slemankab.Go.Id. Deskripsi-Sleman-Smart-Regency.Pdf.

Sutiana, I. (2018). Pengembangan E-Government Terintegrasi Menuju Sleman Smart Regency

Tobing, D. H., Herdiyanto, Y. K., Astiti, D. P., Rustika, I. M., Indrawati, K. R., Susilawati, L. K. P. A., \& All, E. (2016). Bahan Ajar Metode Penelitian Kualitatif. Program Studi Psikologi Fakultas Kedokteran Universitas Udaya, 1-41..

Utomo, C. E., \& Hariadi, M. (2016). Strategi Pembangunan Smart City Dan Tantangannya Bagi Masyarakat Kota. J. Strateg. Dan Bisnis, 4(2), 159-176.

Widodo, N. (2016). Pengembangan E-Government Di Pemerintahan Daerah Dalam Rangka Mewujudkan Smart City (Studi Di Pemerintah Daerah Kota Malang). Jurnal Ilmiah Administrasi Publik, 2(4).

Winardi S, Kom S. 2017. Konsep Pengembangan Kabupaten Yang Cerdas ( Studi Kasus: Kabupaten Sleman , Yogyakarta ). Xii: 100-110.

Yudatama, U., Kunci, K., \& Cerdas, K. (2013). Pengukuran Penerapan Teknologi Informasi Untuk Membangun Smart City. In Konf. Nas. Si 